\title{
Geothermal heat pump system assisted by geothermal hot spring
}

\author{
M. Nakagawa ${ }^{1}$ and Y. Koizumi ${ }^{1, a}$ \\ ${ }^{1}$ Colorado School of Mines, Golden, Colorado, USA \\ ${ }^{a}$ now at: Kajima Corporation, Tokyo, Japan
}

Correspondence to: M. Nakagawa (mnakagaw@mines.edu)

Received: 3 August 2015 - Revised: 16 November 2015 - Accepted: 30 November 2015 - Published: 15 January 2016

\begin{abstract}
The authors propose a hybrid geothermal heat pump system that could cool buildings in summer and melt snow on the pedestrian sidewalks in winter, utilizing cold mine water and hot spring water. In the proposed system, mine water would be used as cold thermal energy storage, and the heat from the hot spring after its commercial use would be used to melt snow for a certain section of sidewalks. Neither of these sources is viable for direct use application of geothermal resources, however, they become contributing energy factors without producing any greenhouse gases. To assess the feasibility of the proposed system, a series of temperature measurements in the Edgar Mine (Colorado School of Mines' experimental mine) in Idaho Springs, Colorado, were first conducted, and heat/mass transfer analyses of geothermal hot spring water was carried out. The result of the temperature measurements proved that the temperature of Edgar Mine would be low enough to store cold groundwater for use in summer. The heat loss of the hot spring water during its transportation was also calculated, and the heat requirement for snow melt was compared with the heat available from the hot spring water. It was concluded that the heat supply in the proposed usage of hot spring water was insufficient to melt the snow for the entire area that was initially proposed. This feasibility study should serve as an example of "local consumption of locally available energy". If communities start harnessing economically viable local energy in a responsible manner, there will be a foundation upon which to build a sustainable community.
\end{abstract}

1

\section{Introduction}

Geothermal energy is a safe, 24/7 renewable energy source with a unique ability for cascading usage, thus being well suited for use in the development of a sustainable community. For example, Hachijojima is a volcanic island located $300 \mathrm{~km}$ south of Tokyo, Japan with a population of about 9500 according to Yamashita et al. (2000). The Hachijojima Geothermal Power Station, operated by the Tokyo Electronic Power Company (TEPCO) since 1999, has the rated output of $3300 \mathrm{~kW}$ of electricity to meet about $30 \%$ of the electricity demand for this isolated island community. Before commercial operation of the geothermal power plant, all electricity demand was met by a diesel power station. In addition to the power generation, the $43^{\circ} \mathrm{C}$ condensed vapor is utilized for heating greenhouses. This is a good example of a sustainable energy utilization system within a community, with local consumption of locally produced energy through a cascading use of geothermal resources.

Although there are no geothermal power stations in Colorado, USA, the state is blessed with low-enthalpy geothermal resources. Local residents and tourists enjoy natural hot springs in many places. The Geo-Heat Center Quarterly Bulletin has described six Colorado hot springs and direct use applications for those springs. One of the side effects of Colorado's booming mining economy during the middle of the 19th century was that there were many mines in the state that were left abandoned when the mining boom ceased.

Abandoned mines are usually environmental and safety liabilities for communities in which they are located, but their potential use as thermal storage resources should not be overlooked. Pingjia and Ning (2011) studied three different usages of abandoned mines, and one of the usages identified in their study is the "Thermal Accumulator". In this 


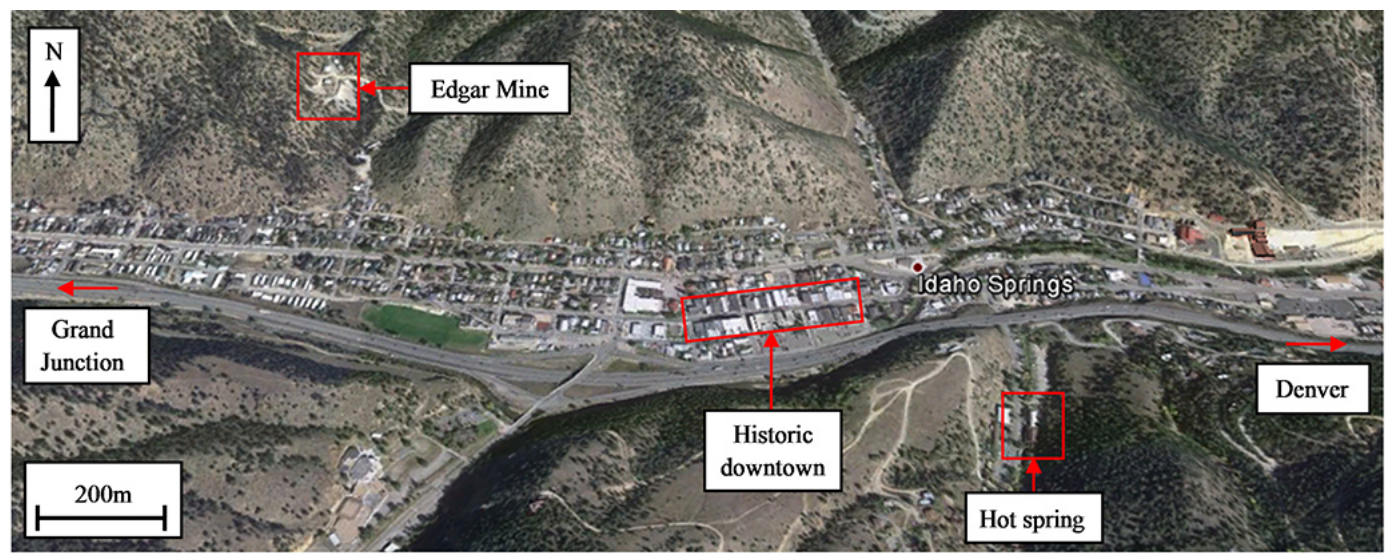

Figure 1. Map of Idaho Springs, Colorado.

usage, two underground mines, a cold mine and a hot mine, would be identified and utilized. Cold water stored in the cold mine would be used in summer, and warm water stored in the hot mine would be used in winter to improve geothermal heat pump efficiency. In a different study, Rodriguez and Diaz (2009) considered a deep underground mine in Spain to be used as a geothermal heat exchanger. According to their measurement, the temperature of the rock mass in the underground mine was a constant $27^{\circ} \mathrm{C}$. Therefore, the authors proposed that cold water be pumped into the mine to run through $1000 \mathrm{~m}$ of galleries in order to gain heat. The heated water would be used to improve the heat pump efficiency of buildings in winter. Furthermore, the authors also conducted an economic analysis and proved that the proposed system would economically be viable.

\section{Geothermal heat pump system assisted by a geothermal hot spring}

\subsection{General Information about Idaho Springs, Colorado, USA}

The city of Idaho Springs, Colorado, USA, is located about $50 \mathrm{~km}$ west of Denver in the foothills of the Rockies. The town was founded in 1859 by mining prospectors and flourished as a mining community throughout the 1860 s. Today, the town has a population of about 1900 and attracts tourists to its historic downtown, hot spring, and the experimental Edgar Mine located just north of the town. Figure 1 shows the map of the city of Idaho Springs and the locations of the historic downtown, the hot spring, and the Edgar Mine.

\subsection{Proposed hybrid geothermal heat pump system}

The proposed heating/cooling geothermal heat pump system for the city of Idaho Springs can be visualized in Fig. 2. It was assumed that the rock mass temperature in the Edgar Mine would be relatively low since the mine was located at a shallow depth. Therefore, the authors envisioned that the collected cold groundwater would be stored in a closed sec-

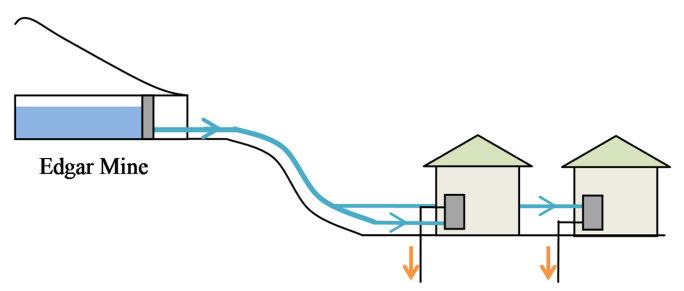

(a) System for summer

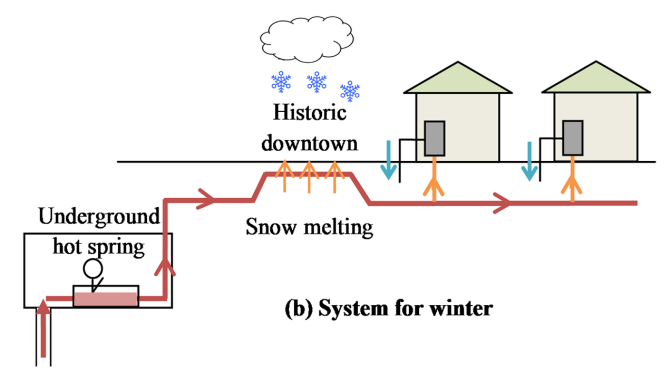

Figure 2. Proposed system for Idaho Springs.

tion of the Edgar Mine in winter and used to cool down the condensers of heat pumps in summer as shown in Fig. 3a. In this way, the efficiency of heat pumps would be improved. In winter, geothermal hot spring water used for commercial bathing would be transported to the historic downtown and used to melt the snow on the pedestrian sidewalks. Furthermore, any residual heat from the hot spring water after snow melting could be used to heat the heat pump evaporators, which would improve the efficiency of the heat pumps (Fig. 3b).

As reviewed in the previous section, the use of a mine to improve heat pump efficiency is not a new idea. For example, Shiba (2008) also reported a case study in which hot spring water consumed in a public bathing facility was re-used to improve heat pump efficiency of buildings in Japan. However, to our best knowledge, we know of no case study in which a mine and hot spring are jointly utilized to assist in 


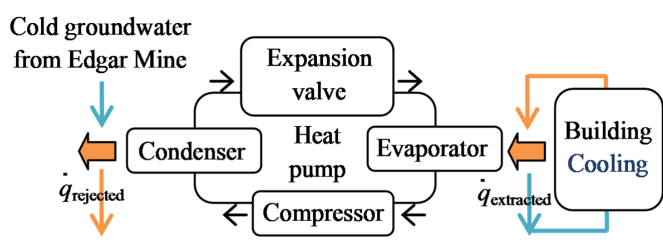

(a) Interaction in summer

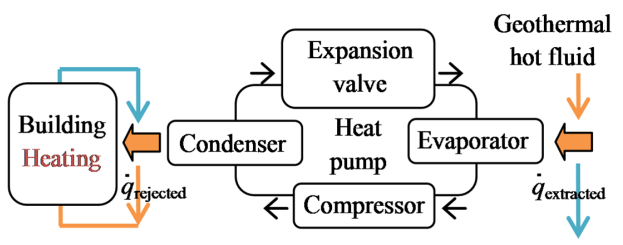

(b) Interaction in winter

Figure 3. Interaction between proposed system, heat pump, and building.

improving the efficiency of a geothermal heat pump system. The close proximity of a hot spring and available mine also makes the location of Idaho Springs and its potential distribution of a geothermal resource unique.

We also point out that there are acceptable flow and temperature range with heat pump source water. The extended range water-water heat pumps prefer a source and load flow rate of 2.5 to $3.0 \mathrm{gpm}$ per nominal ton of capacity, i.e., 0.16 to $0.19 \mathrm{~L} \mathrm{~s}^{-1}$ per $3.5 \mathrm{~kW}$. For most heat pumps (water-water or water-air) using R410a refrigerant for heating, $27^{\circ} \mathrm{C}$ entering water temperature on the source side is the theoretical maximum for reliable operation to produce a leaving water temperature on the load side of $49^{\circ} \mathrm{C}$.

\section{Temperature measurement in the Edgar Mine}

The Edgar Mine produced high-grade silver, gold, lead and copper in the mid 19th century. Colorado School of Mines (CSM) acquired the Edgar Mine in 1921 when a bankrupt mining company agreed to lease it to the school, and CSM has been using the mine for education and research ever since. As an example of its use by the school, junior students in the Mining Engineering Department take a course entitled "Mining Engineering Laboratory" at the Edgar Mine where they receive practical training in operating jackleg drills, jumbo drills, load-haul-dump machines, etc. In other classes, students gain hands-on experience in underground mine surveying, geological mapping, mine ventilation field studies, mine safety, and so on. Photo 1 shows the entrance of the Edgar Mine (Miami Tunnel), and Photo 2 shows a classroom inside the mine. Research is conducted at the Edgar Mine by numerous academic, government, and industry groups including the CSM Mining Engineering Department, the National Institute for Occupational
Safety and Health (NIOSH), the US Army, the US Department of Energy and others. Research topics cover tunnel detection, blasting, rock mechanics, development of a model circulation system for geothermal study, and development of new mining equipment and methods. For more information, the CSM website is available using the following link: http://inside.mines.edu/Mining-Edgar-Mine.

\subsection{Temperature measurement}

In order to assess the thermal capacity of the Edgar Mine, the temperature field inside the Mine was mapped. Temperature measurements were carried out on three different dates; 17 September, 24 October, and 25 November of 2013. Figure 4 shows the data for temperature, precipitation, and snowfall in Idaho Springs in 2013. The data were obtained from the website of AccuWeather.com. The ambient temperature decreased significantly during the measurement period. Measurements taken include the surface temperature of the rock mass, ambient temperature, and humidity at the 24 locations shown in Fig. 5. There are two main tunnels in the Edgar Mine. The eastern tunnel is called the Miami Tunnel, and the western tunnel the Army Tunnel. The height and width of the Miami Tunnel are about 2 and $2 \mathrm{~m}$, and those of the Army Tunnel are about 4 and $5 \mathrm{~m}$. An infrared thermometer (Fluke, Model: 62Max) was used to measure the rock surface temperature as shown in Photo 3. The temperature of groundwater accumulated at location 21 was also measured. The area between the entrance of the Army Tunnel (Location 24) and the location 19 was wet during this period.

\subsection{The temperature mapping in the Edgar Mine}

The measured temperatures of the rock mass surface at the 24 locations are shown in Fig. 5. The temperature measured near the entrance of the two tunnels decreased during the three measurements due to the influence of the ambient temperature. On the other hand, the temperature inside the mine was stable. The highest surface temperature was always measured at location 9 (U.S. Geological Survey (USGS) classroom), and it was about $12.5^{\circ} \mathrm{C}$. The second highest temperature of $12^{\circ} \mathrm{C}$ was measured at location 6 .

Compared to the surface temperature of $27^{\circ} \mathrm{C}$ of the rock mass that was reported in the paper by Rodriguez and Diaz (2009), the surface temperature of the rock mass in the Edgar Mine is much lower; however, this makes sense because the measured areas in the Edgar Mine has been excavated horizontally on just one level so that the typical temperature gradient $\left(20-30{ }^{\circ} \mathrm{C} \mathrm{km}^{-1}\right)$ in depth is not expected.

Figure $6 \mathrm{a}$ and $\mathrm{b}$ show how the measured rock surface and the ambient temperatures change with the distance from the entrance. More specifically, the temperatures measured at locations 1, 2, 3, 4, 5, and 6 are shown in Fig. 6a, and the temperatures measured at locations 18, 19, 21, 23, and 24 are shown in Fig. 6b. Comparing the surface temperatures 


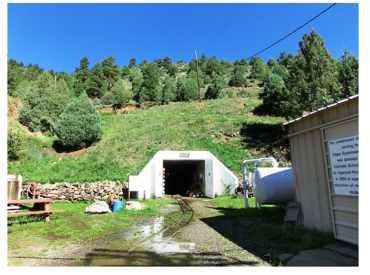

Photo 1: Entrance of Edgar Mine (Miami Tunnel, Location 1 in Figure 5)

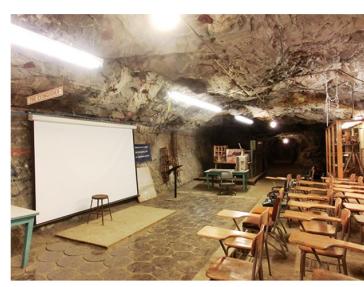

Photo 2: USGS Classroom inside Edgar Mine (Location 9 in Figure 5)

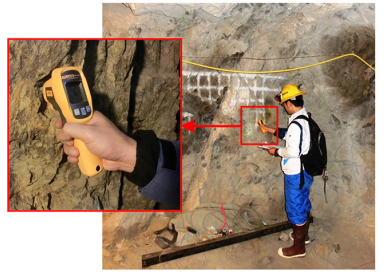

Photo 3: Measurement of rock surface temperature using an infrared thermometer

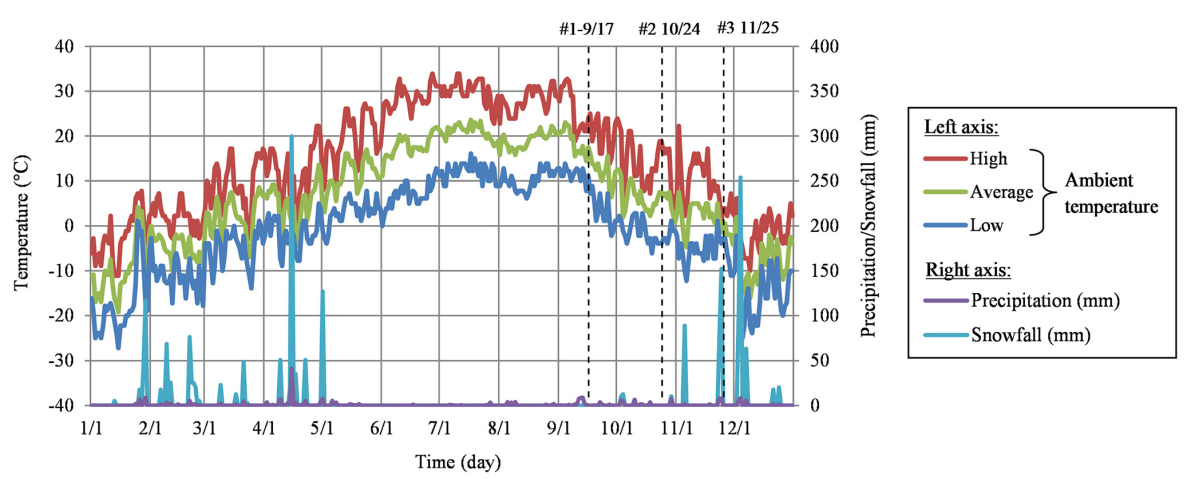

Figure 4. Ambient temperature, precipitation, and snowfall in Idaho Springs.

for locations near the entrance to each of the two tunnels, it is found that the surface temperature increases with the increasing distance from the entrance in the Miami Tunnel (Fig. 6a), and the surface temperatures at locations 4,5 , and 6 show no significant difference between the three measurement dates even though the ambient temperature decreases. Figure $6 b$, on the other hand, indicates that the surface temperature does not increase as the distance becomes greater in the Army Tunnel. Additionally, the surface temperatures shown in Fig. $6 \mathrm{~b}$ are significantly different for each of the three measurements.

In order to understand the difference in the temperature profiles between the Miami Tunnel and the Army Tunnel, the relationship between the cover that is defined as the difference between the elevation of ground surface and that of the tunnel and the distance from the entrance is shown in Fig. 7. It can be seen that the cover above the Army Tunnel does not increase as much as that for the Miami Tunnel. The heat is transferred through the rock mass by conduction since no significant wind blows inside the underground mine. Therefore, as the cover becomes greater, the surface temperature of the rock mass is less influenced by the ambient temperature outside the Edgar Mine. The rock surface temperatures at locations 4,5 , and 6 , with the cover greater than $150 \mathrm{~m}$, is considered to be independent of the ambient temperature outside the mine. Figure 7 also shows the different topography above the Miami Tunnel and the Army Tunnel, which should explain why the Miami Tunnel is dry and the Army Tunnel is wetter. The thin and relatively flat cover above the
Army Tunnel provide more opportunity for the surface water to permeate through to the tunnel.

In conclusion, it is found that the surface temperature of the rock mass in the Edgar Mine is relatively low due to its shallow depth. Therefore, the mine would be suitable for thermal energy storage in which cold groundwater would be stored in winter and used in summer as proposed in Fig. 2. Our recommendation is to utilize the groundwater that is naturally flowing in the mine in a designated storage area.

\section{Temperature loss of transported hot spring water}

In the proposed system, hot spring water will be transported from the hot spring to the east end of historic downtown area through a pipe buried in the ground. In this section, the temperature loss of the transported hot spring water is estimated.

\subsection{Temperature profile of the ground at various depths}

In order to understand the heat transfer between the flowing hot spring water and the ground, the ground temperature $T\left({ }^{\circ} \mathrm{C}\right)$ is first obtained following Kasuda and Achenbach (1965).

$$
\begin{aligned}
T & =T_{\text {mean }}-T_{\text {amp }} \times \exp \left[-D\left(\frac{\pi}{365 \alpha}\right)\right] \\
& \times \cos \left\{\frac{2 \pi}{365}\left[t-t_{\text {shift }}-\frac{D}{2}\left(\frac{365}{\pi \alpha}\right)\right]\right\},
\end{aligned}
$$

where $T_{\text {mean }}, T_{\text {amp }}, D, \alpha, t, t_{\text {shift }}$ are the mean surface temperature, the amplitude of surface temperature, the depth below the surface, thermal diffusivity of the ground, time (day), 


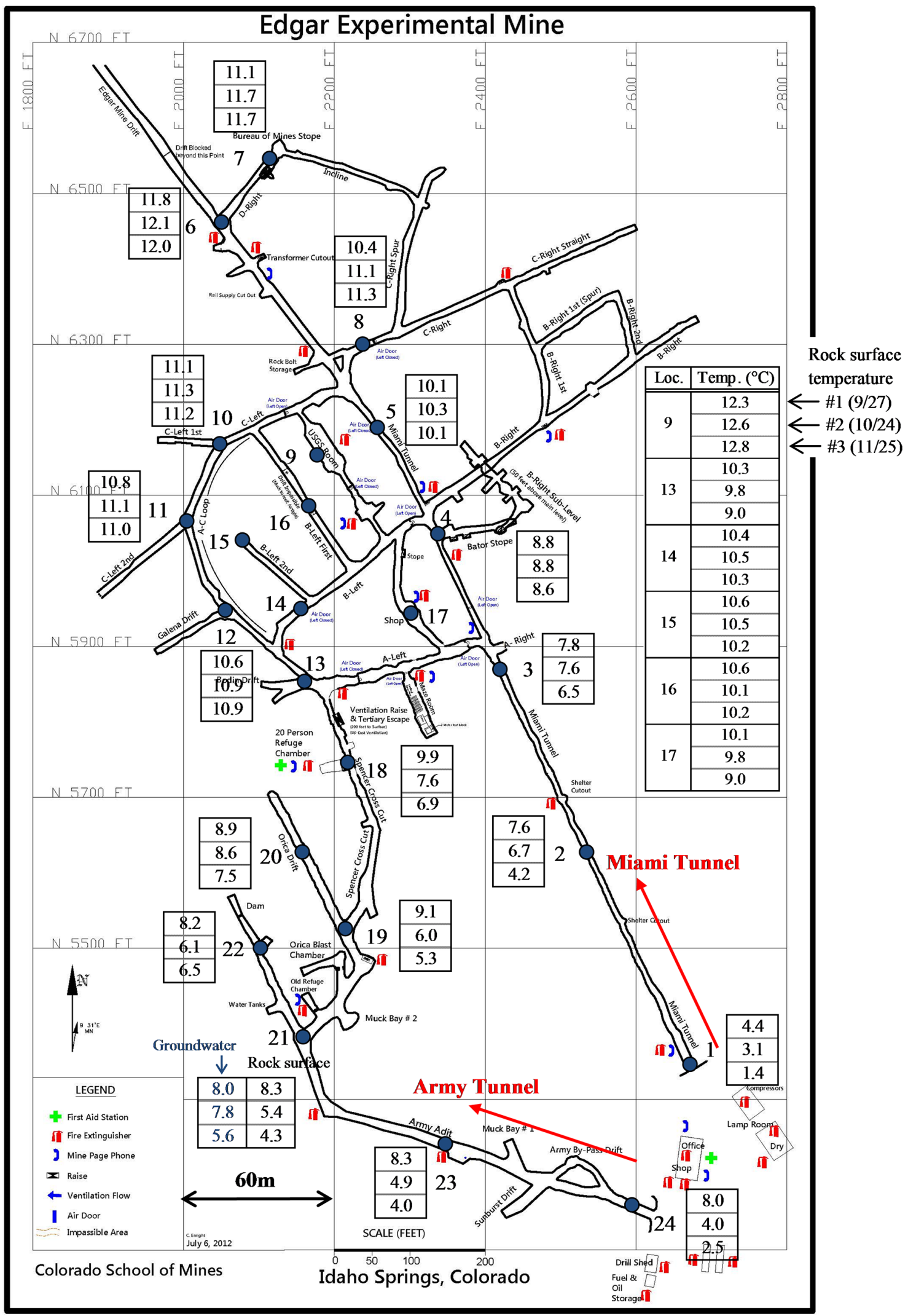

Figure 5. Map of Edgar Mine and rock surface temperature at 24 locations. 


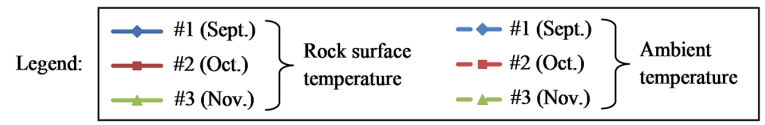

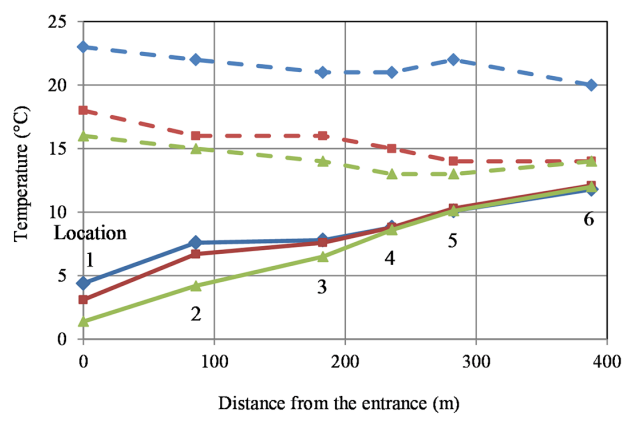

(a) Miami Tunnel

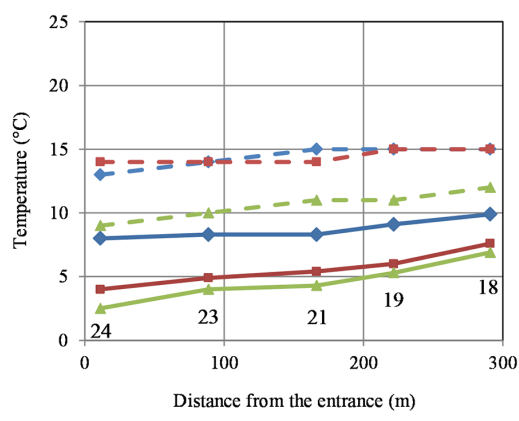

(b) Army Tunnel

Figure 6. Relationship between temperature and distance from the entrance.

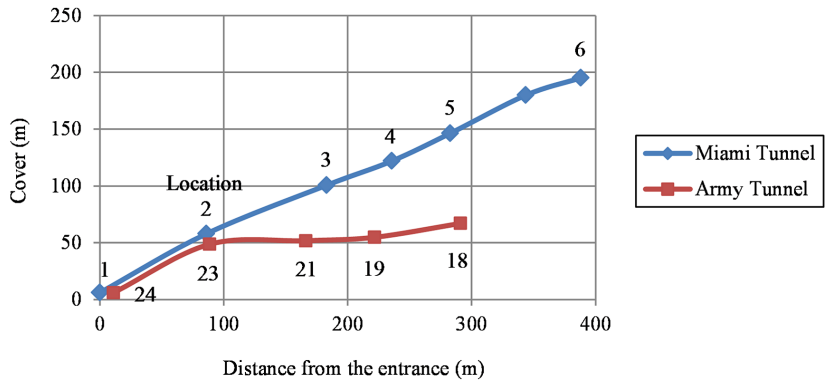

Figure 7. Relationship between cover and distance from the entrance.

and day of the year of the minimum surface temperature, respectively. We set $T_{\text {mean }}$ to be $6.7^{\circ} \mathrm{C}$ defined by the annual average air temperature; $T_{\mathrm{amp}}$ to be $23.7^{\circ} \mathrm{C}$ defined as the average between the maximum, $29.9{ }^{\circ} \mathrm{C}$, and the minimum, $-17.5^{\circ} \mathrm{C}$, air temperature in July and January, respectively; $D$ to be the depth in meters; $\alpha$ to be $1.19 \times 10^{-2} \mathrm{~m}^{2}$ day $^{-1}$ estimated value of thermal diffusivity of the ground; $t$ to be the number of days for the present calculation; $t_{\text {shift }}$ to be 15 days in January defined by the number of days of the year with the minimum surface temperature.

Figure 8 shows the temperature profile in the ground at various depths and indicates that the ground temperature becomes more or less a constant value of $6.7^{\circ} \mathrm{C}$ at the depth of approximately $6 \mathrm{~m}$. Considering potentially significant excavation costs, we assume that the pipe is buried at the depth of $2 \mathrm{~m}$, at which the ground temperature is not exactly constant but allows us to assume a constant temperature of $6.7^{\circ} \mathrm{C}$ to simplify the calculation hereafter.

\subsection{Temperature loss estimation}

Figure 9 shows the schematic representation of the hot spring water flowing to the historic downtown. According to Rep-

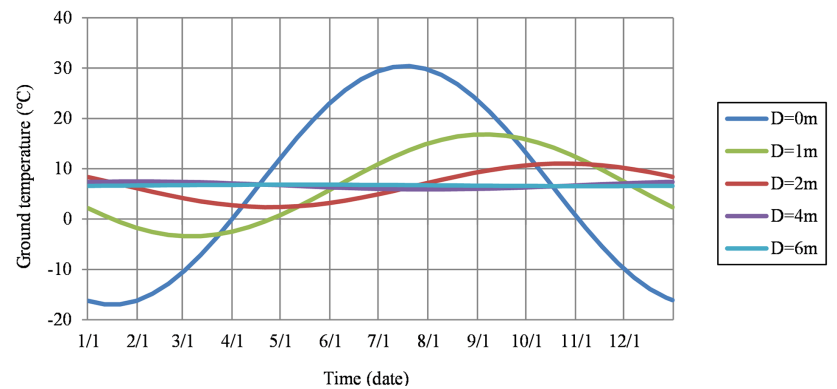

Figure 8. Ground temperature as a function of time and depth.

plier et al. (1982), the flow rate of the geothermal well used by the hot spring is $136 \mathrm{~L} \mathrm{~min}^{-1}$. Considering $25 \%$ loss of the flow, the flow rate is assumed to be $100 \mathrm{~L} \mathrm{~min}^{-1}$. Under the conditions shown in the figure, the temperature loss was calculated as follows.

The Reynolds number of the internal flow through a pipe, $R e_{\mathrm{D}}$ is

$R e_{\mathrm{D}}=\frac{\rho u_{m} D_{i}}{\mu}=\frac{995.0 \times 0.212 \times 0.1}{7.69 \times 10^{-4}}=27430$,

where $\rho, \mu, \quad u_{m}$ are density $\left(\mathrm{kg} \mathrm{m}^{-3}\right)$ and viscosity $\left(N \times \mathrm{s} \mathrm{m}^{-2}\right)$ of the fluid, and internal flow rate $\left(\mathrm{m} \mathrm{s}^{-1}\right)$.

$R e_{\mathrm{D}}$ is larger than 2300 indicating that the flow is turbulent. As the temperature of the fluid is higher than that of the surrounding ground temperature, the following equation can be applied to calculate the Nusselt number, $N u_{\mathrm{D}}$ :

$N u_{\mathrm{D}}=0.023 \times R e^{0.8} \times P r^{0.3}=0.023 \times 27430^{0.8} \times 5.2^{0.3}=134.0$,

where $\operatorname{Pr}$ is Prandtl number. 


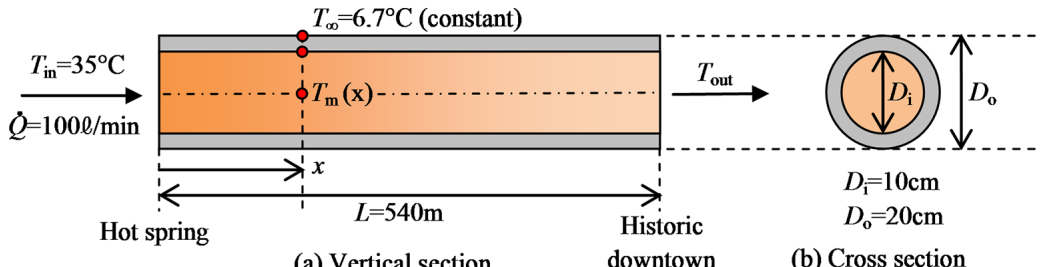

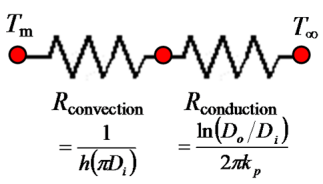

(c) Thermal circuit

(a) Vertical section

downtown

(b) Cross section

Figure 9. Schematic representation of the geothermal hot fluid flowing from hot spring to historic downtown.

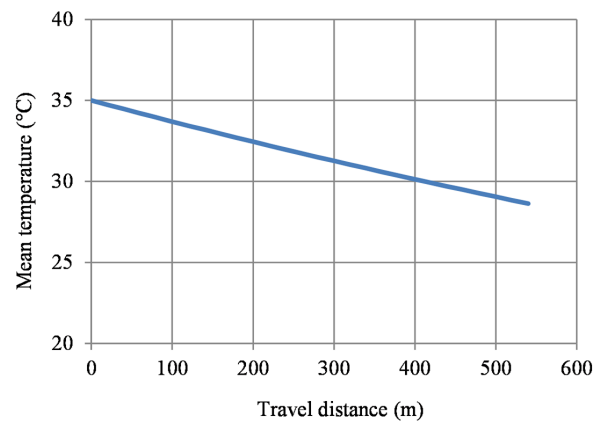

Figure 10. Relationship between mean temperature of geothermal hot fluid and travel distance.

Convection heat transfer coefficient, $h\left(\mathrm{~W} \mathrm{~m}^{-2} \times \mathrm{K}\right)$ is

$h=\frac{N u_{\mathrm{D}} \times k}{D_{i}}=\frac{134.0 \times 0.62}{0.1}=830.8$,

where $k$ is the thermal conductivity of the fluid $\left(\mathrm{W} \mathrm{m}^{-2} \times \mathrm{K}\right)$.

Total thermal resistance per unit length, $R_{\mathrm{tot}}\left(\mathrm{m} \times \mathrm{K} \mathrm{W}^{-1}\right)$ is

$$
\begin{aligned}
R_{\mathrm{tot}} & =R_{\mathrm{conv}}+R_{\mathrm{cond}}=\frac{1}{h\left(\pi D_{i}\right)}+\frac{\ln \left(D_{o} / D_{i}\right)}{2 \pi k_{\mathrm{p}}} \\
& =\frac{1}{830.8 \times(\pi \times 0.1)}+\frac{\ln (0.2 / 0.1)}{2 \times \pi \times 0.16}=0.306,
\end{aligned}
$$

where $k_{\mathrm{p}}$ is the thermal conductivity of a pipe $\left(\mathrm{W} \mathrm{m}^{-1} \times \mathrm{K}\right)$.

$$
\begin{aligned}
\frac{T_{\infty}-T_{x}}{T_{\infty}-T_{\text {in }}} & =\exp \left(-\frac{x}{\dot{m} c_{p} R_{\mathrm{tot}}}\right) T_{x} \\
& =6.7-\exp \left(-\frac{x}{1.66 \times 4178 \times 0.306}\right) \\
& \times(6.7-35),
\end{aligned}
$$

where $T_{x}, T_{\infty}, T_{\text {in }}, m, c_{p}$ are mean temperature at $x=x\left({ }^{\circ} \mathrm{C}\right)$, constant surface temperature $\left({ }^{\circ} \mathrm{C}\right)$, inlet temperature $\left({ }^{\circ} \mathrm{C}\right)$, mass flow rate $\left(\mathrm{kg} \mathrm{s}^{-1}\right)$, and specific heat of the fluid $\left(\mathrm{J} \mathrm{kg}^{-1} \times \mathrm{K}\right)$.

Figure 10 shows the relationship between the mean temperature of the geothermal hot spring water and its traveled distance. It is found that the temperature would decrease from 35 to $28.6^{\circ} \mathrm{C}$ while it is transported to the historic

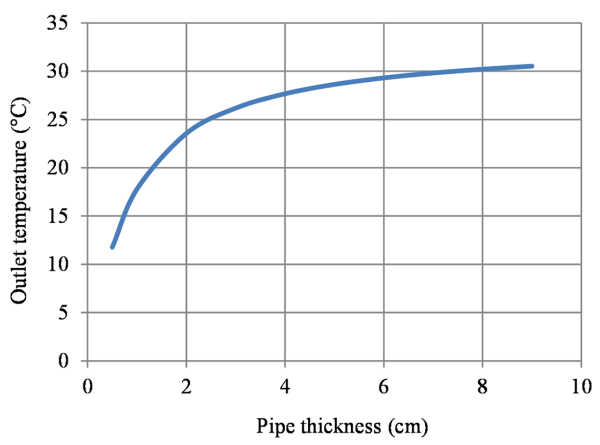

Figure 11. Relationship between outlet temperature of geothermal hot fluid and pipe thickness.

downtown over the distance of $540 \mathrm{~m}$. In this calculation, the thickness of a pipe was assumed to be $5 \mathrm{~cm}$. Figure 11 shows the result of a parametric study when the thickness of the pipe is varied from 1 to $9 \mathrm{~cm}$. Figure 11 indicates that the outlet temperature monotonically increases with increasing thickness, but beyond the thickness of $5 \mathrm{~cm}$, the increase of the temperature becomes very modest. Considering its high cost and the difficulties working with thick pipes, $5 \mathrm{~cm}$ thickness assumed in the calculation above is the most reasonable.

\section{Energy balance analysis for snow melting}

The exiting temperature $28.6^{\circ} \mathrm{C}$ is used to melt snow and to improve the heat pump efficiency of the buildings in the historic downtown. In this section, the feasibility of the designed snow melting system is discussed by comparing heat supply and heat requirement for snow melting.

\subsection{Heat supply from the hot spring water to pedestrian sidewalks}

Figure 12 shows the design of the proposed snow melting system for the sidewalks of the historic downtown. The hot water transported from the hot spring source flows through the pipe system in the north and south pedestrian sidewalks. The depth, the spacing, and the size of buried pipes are appropriately adapted after having reviewed two previous case studies in which similar snow melting systems were installed. One case study covers the system in Kla- 


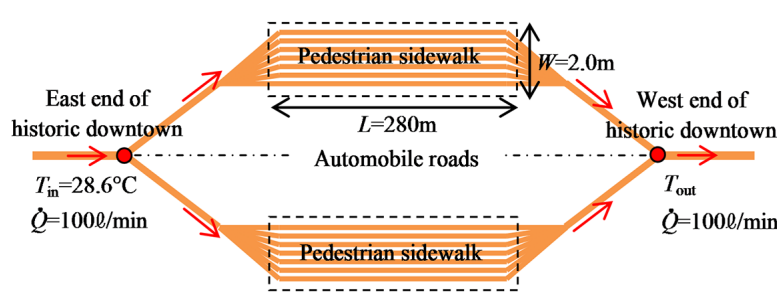

(a) Plan view

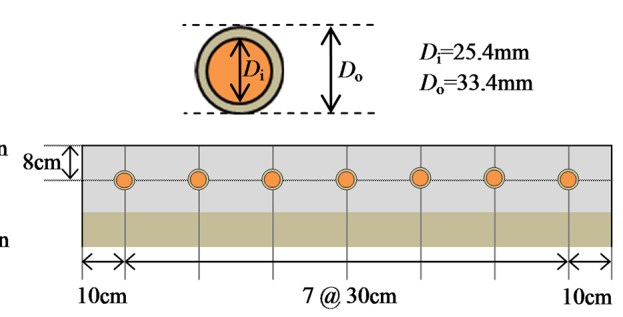

(b) Cross sectional view

Figure 12. Schematic representation of the geothermal hot fluid flowing from hot spring to historic downtown.

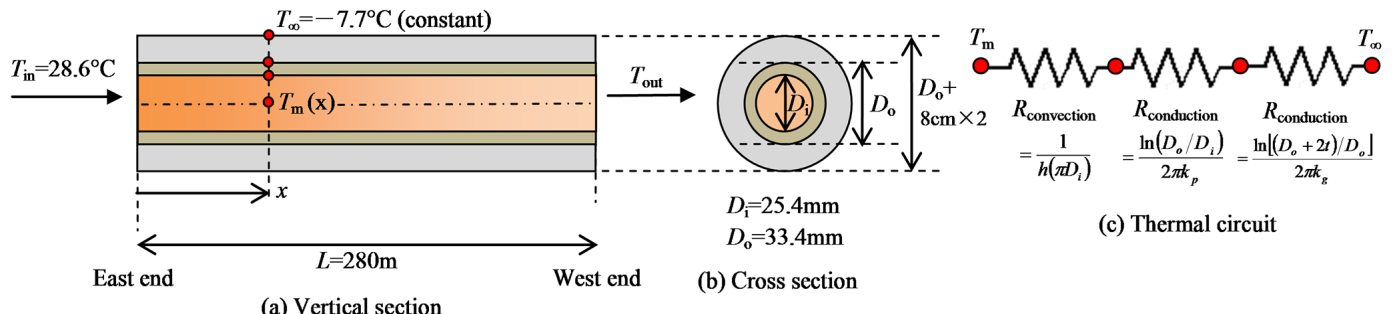

Figure 13. Schematic representation of geothermal hot fluid flowing from hot spring to historic downtown.

math Falls, Oregon, reported by Lund (1999) and the other covers the system in Sapporo, Japan, reported by Sato and Sekioka (1979).

In order to calculate the heat supply from the hot spring water to the pedestrian sidewalks, the temperature decrease of the flow through the pipes buried in the sidewalks was calculated in the same way as the calculation of the temperature loss in Sect. 4. However, the buried depth of the pipes shown in Fig. 12 is only $8 \mathrm{~cm}$, while that of the pipe in the previous section was assumed to be $2 \mathrm{~m}$. Therefore, the geothermal hot water would significantly be influenced by cold ambient temperature. Thus, it is assumed that the flow is cooled down by the constant temperature, $-7.7^{\circ} \mathrm{C}$, as shown in Fig. 13. The average temperature of the ground surface in 2013 was $-7.7^{\circ} \mathrm{C}$ between 1 November and 30 April, the average months of snowfall in Idaho Springs as shown in Fig. 4.

The outlet temperature $T_{\text {out }}$ was found to be $3.1^{\circ} \mathrm{C}$. Therefore, the heat supply from the geothermal hot fluid to the surrounding ground $q(\mathrm{~W})$ is

$$
\begin{aligned}
q & =\dot{m} c_{p}\left(T_{\text {in }}-T_{\text {out }}\right)=1.66 \times 4184 \times(28.6-3.1) \\
& =177.108 \mathrm{~W}=177.1 \mathrm{~kW} .
\end{aligned}
$$

According to Adlam (1950), $70 \%$ of the heat is usefully consumed for snow melting, because approximately $8-10 \%$ is emitted to the atmosphere and approximately $20-22 \%$ is lost downwards to the ground. Therefore, the available heat for snow melting is

$q_{\text {available }}=0.7 \times q=0.7 \times 177.1=124.0 \mathrm{~kW}$.

The outlet temperature of the geothermal fluid $\left(3.1^{\circ} \mathrm{C}\right)$ is so cold that it could not be used to heat up an evaporator of a heat pump. Therefore, the proposed system shown in Fig. $2 \mathrm{~b}$ is not realistic and should be modified. The geothermal hot fluid flows $8 \mathrm{~cm}$ under the pedestrian sidewalks only on snowy days. Otherwise, it is transported to a heat pump of each building directly so that the heat can be used more effectively.

\subsection{Heat flux requirement for snow melting}

Chapman and Katunich (1956) estimated the required total heat flux for snow melting, $q_{0}\left(\mathrm{~W} \mathrm{~m}^{-2}\right)$ as follows:

$q_{0}=q_{\mathrm{s}}+q_{m}+A_{\mathrm{r}}\left(q_{h}+q_{\mathrm{e}}\right)$,

where $q_{\mathrm{s}}, q_{m}, A_{\mathrm{r}}, q_{h}, q_{\mathrm{e}}$ are sensible heat flux $\left(\mathrm{W} \mathrm{m}^{-2}\right)$, latent heat flux $\left(\mathrm{W} \mathrm{m}^{-2}\right)$, snow-free area ratio, convective and radiative heat flux from snow-free surface $\left(\mathrm{W} \mathrm{m}^{-2}\right)$, and heat flux of evaporation $\left(\mathrm{W} \mathrm{m}^{-2}\right)$, respectively. According to Chapman and Katunich (1956), when $A_{\mathrm{r}}$ is 1.0 , the system melts snow rapidly enough that no accumulation of snow occurs. However, this condition requires the maximum energy supply. When $A_{\mathrm{r}}$ is 0 , the surface is covered with snow of sufficient thickness. This condition is not desirable but could be tolerable when time for snow clearance is not critical. Chapman and Katunich (1956) recommended that an intermediate value of $A_{\mathrm{r}}=0.5$ would be used for many non-critical situations. Thus, in this calculation, three required total heat fluxes for snow melting were calculated when $A_{\mathrm{r}}$ is $0,0.5$ and 1.0, and the required heat with $A_{\mathrm{r}}=0.5$ is considered to be the most important value in practice. The document prepared by ASHRAE (American Society of Heating, Refrigerating and Air-Conditioning Engineers) (2011) is used to calculate each heat flux as shown below. 
Sensible heat flux, $q_{\mathrm{s}}\left(\mathrm{W} \mathrm{m}^{-2}\right)$ is

$$
\begin{aligned}
q_{\mathrm{s}} & =\rho_{\mathrm{water}} s\left[c_{p, \text { ice }}\left(t_{s}-t_{\mathrm{a}}\right)+c_{p, \text { water }}\left(t_{\mathrm{f}}-t_{s}\right)\right] / c_{1} \\
& =1000 \times \frac{2.36}{3.6 \times 10^{6}} \\
& {[2100 \times(0+6.2)+4290 \times(0.56-0)]=10.1, }
\end{aligned}
$$

where $\rho_{\text {water }}, s, c_{p}$, ice, $c_{p \text {, water }}, t_{\mathrm{a}}, t_{\mathrm{f}}, t_{s}, c_{1}$ are density of water $\left(\mathrm{kg} \mathrm{m}^{-3}\right)$, snowfall rate water equivalent $\left(\mathrm{mm} \mathrm{h}^{-1}\right)$, specific heat of ice $\left(\mathrm{J} \mathrm{kg}^{-1} \times \mathrm{K}\right)$, specific heat of water $\left(\mathrm{J} \mathrm{kg}^{-1} \times \mathrm{K}\right)$, ambient temperature coincident with snowfall $\left({ }^{\circ} \mathrm{C}\right)$, liquid film temperature $\left({ }^{\circ} \mathrm{C}\right)$, melting temperature $\left({ }^{\circ} \mathrm{C}\right)$, and conversion factor. We find that it snowed in Idaho Springs for a total of 34 days in 2013. Therefore, the ambient temperature during the snowfall is assumed to be $-6.2^{\circ} \mathrm{C}$, which is the average of ambient temperature of the 34 snowy days. Snowfall rate water equivalent is assumed $2.36 \mathrm{~mm} \mathrm{~h}^{-1}$ as the average snowfall rate per day is $56.6 \mathrm{~mm} \mathrm{day}^{-1}$ in Idaho Springs.

Latent heat flux, $q_{m}\left(\mathrm{~W} \mathrm{~m}^{-2}\right)$ is

$$
q_{m}=\rho_{\text {water }} s h_{i \mathrm{f}} / c_{1}=1000 \times \frac{2.36}{3.6 \times 10^{6}} \times 334000=219.0,
$$

where $h_{i \mathrm{f}}$ is heat of fusion of snow $\left(\mathrm{J} \mathrm{kg}^{-1}\right)$.

Convective and radiative heat flux from a snow-free surface, $q_{h}\left(\mathrm{~W} \mathrm{~m}^{-2}\right)$, is

$$
\begin{aligned}
q_{h} & =h_{\mathrm{c}}\left(t_{s}-t_{\mathrm{a}}\right)+\sigma \varepsilon_{\mathrm{s}}\left(T_{\mathrm{f}}^{4}-T_{a}^{4}\right)=12.3 \times(0.56+6.2) \\
& +\left(5.67 \times 10^{-8}\right)(0.9)\left(273.7^{4}-264.9^{4}\right)=110.7,
\end{aligned}
$$

$$
\begin{aligned}
h_{\mathrm{c}} & =0.037\left(\frac{k_{\mathrm{air}}}{L}\right) \operatorname{Re}_{\mathrm{L}}^{0.8} \operatorname{Pr}^{\frac{1}{3}} \\
& =0.037\left(\frac{k_{\mathrm{air}}}{L}\right)\left(\frac{V L}{v_{\text {air }}} c_{2}\right)^{0.8} \operatorname{Pr}^{\frac{1}{3}} \\
& =0.037\left(\frac{0.0235}{6.1}\right)\left(\frac{10.0 \times 2.0 \times 0.278}{1.3 \times 10^{-5}}\right)^{0.8} \\
& (0.7)^{\frac{1}{3}}=12.3,
\end{aligned}
$$

where $h_{\mathrm{c}}, T_{\mathrm{f}}, T_{\mathrm{MR}}, \sigma, \varepsilon_{\mathrm{s}}, k_{\mathrm{air}}, L, R e_{\mathrm{L}}, P r, V, v_{\mathrm{air}}, c_{2}$ are convection heat transfer coefficient for turbulent flow $\left(\mathrm{W} \mathrm{m}^{-2}\right)$, liquid film temperature $(\mathrm{K})$, mean radiant temperature of surroundings (K), Stefan-Boltzmann constant $\left(=5.67 \times 10^{-8} \mathrm{~W} \mathrm{~m}^{-2} \times \mathrm{K}^{4}\right)$, emittance of surface $(=0.7$ assumed), thermal conductivity of air at $t_{\mathrm{a}}\left(\mathrm{W} \mathrm{m}^{-1} \times \mathrm{K}\right)$, characteristic length of slab in direction of wind (m), Reynolds number based on characteristic length $L$, and Prandtl number for air $(=0.7)$, design wind speed near slab surface $\left(=10 \mathrm{~km} \mathrm{~h}^{-1}\right.$ assumed), kinematic viscosity of air $\left(\mathrm{m}^{2} \mathrm{~s}^{-1}\right)$, and conversion factor $(=0.278)$, respectively.
Evaporation heat flux, $q_{\mathrm{e}}\left(\mathrm{W} \mathrm{m}^{-2}\right)$ is

$$
\begin{aligned}
q_{\mathrm{e}} & =\rho_{\text {dry air }} h_{\mathrm{m}}\left(W_{\mathrm{f}}-W_{\mathrm{a}}\right) h_{f g}=1.33 \times 0.0102 \\
& \times(0.00393-0.00160) \times 2499 \times 10^{3}=79.2,
\end{aligned}
$$

$h_{\mathrm{m}}=\left(\frac{P r}{S c}\right)^{\frac{2}{3}} \frac{h_{\mathrm{c}}}{\rho_{\text {dry air }} c_{p, \text { air }}}=\left(\frac{0.7}{0.6}\right)^{\frac{2}{3}} \frac{12.3}{1.33 \times 1005}=0.0102$,

where $h_{\mathrm{m}}, W_{\mathrm{a}}, W_{\mathrm{f}}, h_{f g}, \rho_{\text {dry air }}, S c$ are mass transfer coefficient $\left(\mathrm{m} \mathrm{s}^{-1}\right)$, humidity ratio of ambient air, humidity ratio of saturated air at film surface temperature, heat of vaporization $\left(\mathrm{J} \mathrm{kg}^{-1}\right)$, density of dry air $\left(\mathrm{kg} \mathrm{m}^{-3}\right)$, and Schmidt number $(=0.6)$.

As a result, the required total heat flux for snow melting is $229.1,324.0$, and $418.9 \mathrm{~W} \mathrm{~m}^{-2}$ when $A_{\mathrm{r}}$ is $0,0.5$, and 1.0 , respectively. The area of the pedestrian sidewalks is $1120 \mathrm{~m}^{2}(=280 \mathrm{~m} \times 2 \mathrm{~m} \times 2)$; therefore, the required total heat is $256.6,362.9$, and $469.2 \mathrm{~kW}$ when $A_{\mathrm{r}}$ is $0,0.5$, and 1.0 .

Comparing the heat supply from the geothermal hot fluid $(124.0 \mathrm{~kW})$ with the required total heat shown above, it is found that the heat supply would be insufficient to melt snow even when $A_{\mathrm{r}}$ is 0 for the entire section of sidewalks. As shown in Eq. (7), the heat supply depends on mass flow rate and the difference between inlet and outlet temperature. As it is difficult to make the temperature difference larger, the required heat would be supplemented by drilling roughly two additional geothermal wells to satisfy the required total heat with $A_{\mathrm{r}}=0.5,362.9 \mathrm{~kW}$. Or the snow melting area should be limited to approximately one-third of the total area of the pedestrian sidewalks.

\section{Conclusion}

In this study, the authors proposed a hybrid geothermal heat pump system that is coupled with mine water and hot spring water. We mapped the temperature profile in the Edgar Mine, assessed its thermal capacity, and analyzed the heat/mass transfer of the geothermal hot spring water.

The temperature measurements showed that the temperature of rock surface was approximately $12{ }^{\circ} \mathrm{C}$ at maximum in the Edgar Mine, and the mine should be designed as a cold thermal energy storage. As the Army Tunnel was wetter and colder than the Miami Tunnel, the Army Tunnel is a more suitable mine tunnel to store cold groundwater from winter to summer. Unlike the Miami Tunnel, however, the rock surface temperature in the Army Tunnel was not constant because of its thinner cover. Therefore, temperature measurement in the Army Tunnel should be continued for the rest of the year to design a cold thermal storage system.

The heat/mass transfer analyses showed that the temperature of the geothermal hot water decreased from 35 to $28.6^{\circ} \mathrm{C}$ when the thickness of a pipe was assumed to be $5 \mathrm{~cm}$ during a $540 \mathrm{~m}$ transportation. In order to minimize this temperature loss, the thickness of a pipe should be much larger than 
$5 \mathrm{~cm}$. However, as the correlation between the pipe thickness and the temperature loss is non-linear, the pipe thickness has to be chosen appropriately considering the cost and ease of construction work.

The energy balance analyses showed that the proposed system would not melt snow-covered pedestrian sidewalks effectively. In order to satisfy the heat requirement with $A_{\mathrm{r}}=0.5$, the heat supply has to be increased approximately three times, which could be achieved by drilling additional geothermal wells if appropriate. Alternatively, additional thermal insulation measures can be taken to reduce the temperature drop. It should be acknowledged that underlayment insulation is very effective on snowmelt slabs to maximize snowmelt performance. With good underlayment insulation and optimized hydronic pipe spacing it may be expected to increase the use of the provided flow and temperature of hot water by $30 \%$ or more, and the snowmelt slab will react faster to melt snow/ice.

Acknowledgements. The authors would like to thank Terry Proffer for his critical review of the manuscript.

Edited by: R. Schulz

Reviewed by: T. Proffer and S. Rumohr

\section{References}

AccuWeather.com: Local weather record of Idaho Springs, CO, USA, available at: http://www.accuweather.com/en/us/ idaho-springs-co/80452/december-weather/337419?monyr=12/ 1/2013\&view=table, last access: 1 January 2014.
Adlam, T. N.: Snow Melting, The Industrial Press, New York, USA, 1950.

ASHRAE: Snow Melting and Freeze Protection, 2011 ASHRAE Handbook - HVAC Applications, 51, 51.1-51.20, 2011.

Chapman, W. P. and Katunich, S.: Heat Requirements of Snow Melting Systems, ASHRAE Tran., 62, 359-372, 1956.

Kusuda, T. and Achenbach, P. P.: Earh Temperature and Thermal Diffusivity at Selected Stations in the United States, Summary of Research Report 8972, National Bureau of Standard, 1965.

Lund, J. W.: Reconstruction of a Pavement Geothermal Deicing System, Geo-Heat Center Quarterly Bulletin, 20, 14-17, 1999.

Pingjia, L. and Ning, C.: Abandoned Coal Mine Tunnels: Future Heating/power Supply Centers, Mining Science and Technology (China), 21, 637-640, 2011.

Repplier, F. N., Zacharakis, T. G., and Ringrose, C. D.: Geothermal Resource Assessment of Idaho Springs, Colorado, Colorado Geological Survey, Golden, Colorado, 1982.

Rodriguez, R. and Diaz, M. B.: Analysis of the Utilization of Mine Galleries as Geothermal Heat Exchangers by Means a Semiempirical Prediction Method, Renew. Energ., 34, 1716-1725, 2009.

Sato, M. and Sekioka, M.: Geothermal Snow Melting at Sapporo, Japan, Geo-Heat Center Quarterly Bulletin, 4, 16-18, 1979.

Shiba, Y.: Ground-Source Heat Pump System, Building Utilities and Piping Work, 2, 20-24, 2008 (in Japanese).

Yamashita, M., Majima, T., Tsujita, M., and Matsuyama, K.: Geothermal Development in Hachijojima, Proceedings, World Geothermal Congress 2000, 28 May-10 June 2000, KyusyuTohoku, Japan, 2000. 